Rev. Inst. Flor . v. 26 n. 1 p. 17-41 2014

http://dx.doi.org/10.4322/rif.2014.002

ISSN impresso 0103-2674/on-line 2178-5031

\title{
COMPOSIÇÃO E ESTRUTURA DA VEGETAÇÃO RIPÁRIA NA SUB-BACIA DO CÓRREGO DO CINTRA (BOTUCATU - SP) ${ }^{1}$
}

\section{COMPOSITION AND STRUCTURE OF THE RIPARIAN FOREST IN THE SUB-WATERSHED OF CINTRA STREAM (BOTUCATU - SP)}

\author{
Ivalde BELLUTA², ${ }^{2}$;osé Pedro Serra VALENTE³ ${ }^{3}$ Lídia Raquel de CARVALHO; \\ Assunta Maria Marques da SILVA; ${ }^{3}$ Vera Lex ENGEL ${ }^{2}$
}

\begin{abstract}
RESUMO - As Cuestas Basálticas apresentam-se na paisagem da região central do Estado de São Paulo e caracterizam-se pela Floresta Estacional Semidecidual. O objetivo deste trabalho foi caracterizar a estrutura, estádio sucessional e a diversidade da mata ripária integrante da sub-bacia do córrego do Cintra, situada na região da Cuesta de Botucatu. O método fitossociológico utilizado em três áreas foi o de ponto-quadrante com dois indivíduos amostrados em cada quadrante e de tamanho $>5 \mathrm{~m} \mathrm{e}<5 \mathrm{~m}$ de altura. Foi utilizado o teste de Friedman na comparação das espécies arbóreas nas três áreas, seguido do teste de Dunn, ao nível de 5\% de significância. Os índices analisados foram dominância relativa - DoR, densidade relativa - DR, e índice de valor de cobertura - IVC, obtidos através de cálculo em planilha eletrônica; o estádio sucessional foi determinado pela proporção relativa entre os números de indivíduos de espécies de diferentes sinúsias identificadas; a diversidade de espécies foi estudada com base nos índices de diversidade de Shannon-Wiener (H'), Pielou (J) e Simpson, conotação 1-D, através do programa Past. Nas três áreas de amostragem foram encontradas 2.241 indivíduos arbóreos de 145 espécies, pertencentes a 55 famílias botânicas, sendo as mais representativas Fabaceae com 16,3\%; Lauraceae, Myrtaceae e Boraginaceae com 7\% cada, totalizando 37,3\% da amostragem total. As espécies com maior DoR, DR e IVC nas áreas 1, 2 e 3 respectivamente foram Calophyllum brasiliense, Piptadenia gonoacantha e Gochnatia polymorpha. $\mathrm{O}$ estádio sucessional na área 1 foi considerado mais tardio, na área 2 intermediário, e pioneiro na área 3, além da diversidade $\left(\mathrm{H}_{\mathrm{A} 1}^{\prime}=4,08 ; \mathrm{H}_{\mathrm{A} 2}^{\prime}=3,79 ; \mathrm{H}_{\mathrm{A} 3}^{\prime}=3,31\right.$ nats/ind $\left.{ }^{-1}\right)$ das espécies, que foi considerada alta e boa equabilidade nas três áreas. Portanto, na área 3 os índices indicaram maior dominância de poucas espécies que está em processo de sucessão, com a necessidade de revegetação e regeneração florestal.
\end{abstract}

Palavras-chave: mata ripária; florística; estádio sucessional; diversidade; sub-bacia hidrográfica.

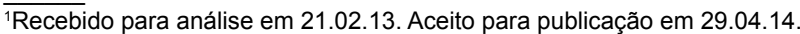

2Unesp Campus de Botucatu, Faculdade de Ciências Agronômicas, Rua José Barbosa de Barros, 1780, $18610-307$ Fazenda Lageado, Botucatu, SP, Brasil. 3Unesp Campus de Botucatu, Instituto de Biociências, Distrito de Rubião Júnior, s/n, Caixa Postal 510, 18618-970, Botucatu, SP, Brasil.

${ }^{4}$ Autor para correspondência: Ivalde Belluta - ibelluta@ibb.unesp.br 


\begin{abstract}
Basaltic Cuestas are located in the middle-west landscapes of São Paulo state and are characterized by Semideciduous Forest. The aim of this study was to characterize the structure, the successional stage and the diversity of the riparian forest of the Cintra stream sub-watershed, located at the region of Botucatu Cuesta. The phytosociological method applied to the three areas was the point-quarter, respectively $>5 \mathrm{~m}$ and $<5 \mathrm{~m}$ of height. The Friedman test was adopted in the comparison among tree species in all three areas and was followed by Dunn's test, at 5\% significance. The analyzed indexes were relative dominance - (DoR), relative density - (DR), and covering index - (IVC), obtained by means of an electronic spreadsheet; the successional stage was determined by the relative proportion among the numbers of individuals of different synusiae species identified; and the diversity of species was studied based on the diversity indexes of Shannon-Wiener (H'), Pielou (J) and Simpson, connotation 1-D, using the software Past. In the three sampling areas, 2,241 arboreal individuals of 145 species were found, which belong to 55 botanical families, and the most representative families were Fabaceae, 16.3\%; Lauraceae, Myrtaceae and Boraginaceae, $7 \%$ each, totaling $37.3 \%$ of the total sampling. The species with the highest DoR, DR and IVC in areas 1,2 and 3, respectively, were Calophyllum brasiliense, Piptadenia gonoacantha and Gochnatia polymorpha. The successional stage in area 1 was considered late, in area 2 was intermediate, and the one in area 3 was pioneer, while the diversity $\left(\mathrm{H}_{\mathrm{A1}}^{\prime}=4.08 ; \mathrm{H}_{\mathrm{A} 2}=3.79 ; \mathrm{H}_{\mathrm{A} 3}=3.31\right.$ nats $/$ ind $\left.^{-1}\right)$ of species was considered high and with good equitability for all 3 areas. Therefore, the indexes indicated greater dominance of a few species in area 3, which is in succession process, requiring reforestation and forest regeneration.
\end{abstract}

Keywords: riparian forest; floristics; successional stage; diversity; catchment.

\section{INTRODUÇÃO}

O município de Botucatu, Estado de São Paulo, está localizado em uma "região de Cuesta Basáltica", que é caracterizada por um relevo íngreme em um dos lados chamado Front (escarpa arenítica-basáltica), com 700 a 920 metros de altitude e marca o início e o limite físico do Planalto Ocidental Paulista. Do outro lado, o Reverso da Cuesta com 400 a $600 \mathrm{~m}$, corresponde a uma descida suave e normalmente longa em direção oeste com cerca de $500 \mathrm{~km}$, na altura da calha do rio Paraná. Entre as peculiaridades que o torna único em todo o mundo, a muralha de $300 \mathrm{~m}$ que separa a linha entre o topo da Cuesta e a depressão periférica (baixada) que se estende por mais de $80 \mathrm{~km}$; a cobertura e a diversidade original da flora, além da riqueza paisagística inigualável nas áreas mais íngremes (Front). Esse relevo, no Brasil, abrange os estados de São Paulo, Minas Gerais e Paraná e, em outros países, são encontrados na África do Sul, Canadá, Europa, México e Índia (Souza et al., 2003; Souza, 2005).
A sub-bacia do Córrego do Cintra, situado na parte sul e no reverso da Cuesta de Botucatu, é parte integrante da sub-bacia do Araquá e este integrante da Bacia Hidrográfica do Tietê. A análise topográfica da sub-bacia mostra que os tributários e o eixo principal do córrego contribuem para a dessecação da região e correm em direção à depressão periférica sentido norte (Estância Turística de Barra Bonita: Rio Tietê). No aspecto florístico da sub-bacia, pode-se observar as diferentes fisionomias vegetais em função da altitude no sentido nascente à foz do Córrego do Cintra (Belluta, 2012).

As baixas similaridades, devido às variações nas características do relevo dentro do município de Botucatu - SP, induzem a muitas divergências entre autores sobre as categorias Montana e Submontana e muitos trabalhos realizados na "região de Cuestas Basálticas" (SOSCuesta, 2013; Biral e Lombardi, 2012; Silva, 2010; Cassola, 2008; Leite, 2002, Fonseca e Rodrigues, 2000; Gabriel, 1990) classificam o tipo florestal da Cuesta Botucatu. 
Juntamente com outros municípios integrantes de áreas de Cuesta do interior do Estado de São Paulo, como a cidade de Analândia (Teixeira e Rodrigues, 2006; Almeida-Scabbia et al., 2011), São Carlos (Silva e Soares, 2003), Itatinga (Ivanauskas et al., 1999) e Itirapina (Kotchetkoff-Henriques e Joly, 1994), definem o tipo de floresta de modo generalizado como Floresta Estacional Semidecidual - FES ou Floresta Mesófila Semidecídua - FMS.

Independente do tipo de floresta, os atributos de uma comunidade vegetal podem variar entre habitats ou entre momentos dentro de um mesmo local. Assim, é preciso entender quais são os fatores ecológicos, históricos, naturais e antrópicos que determinam a estrutura e a composição da vegetação ou provocam sua modificação (Martins, 2009; Ivanauskas et al., 2008). As áreas adjacentes aos cursos d'água e sob influência direta da variação do lençol freático recebem a denominação de zona ripária, parte essencial da paisagem e se constituem no ecossistema de transição entre os ambientes terrestre e aquático de uma bacia hidrográfica. Caracterizam-se por serem altamente produtivas, em função das grandes trocas de nutrientes, energia e elementos bióticos entre os dois ambientes bastante distintos (Arcova, 2006). Nas observações feitas por Vital et al. (2004), ocorre pouco estoque de serapilheira acumulado nessas áreas, apresentando rápida velocidade de decomposição e o rápido aproveitamento de nutrientes pela vegetação, o que favorece seu desenvolvimento.

$\mathrm{Na}$ degradação de uma sub-bacia, o conhecimento dos fatores do meio abiótico e da estrutura florística e fitossociológica da vegetação podem ajudar a apontar as espécies arbóreas mais adaptadas às diversas condições da área local, bem como aquelas indicadoras do estado de conservação nas diversas unidades fitogeográficas. Dada a importância geográfica da região da Cuesta de Botucatu, o objetivo do presente estudo foi caracterizar a estrutura, o estádio sucessional e a diversidade da mata ripária, integrante da sub-bacia do córrego do Cintra. As questões a serem respondidas são: Qual o nível de degradação da formação florestal? Que áreas seriam prioritárias para ações de revegetação ou restauração?

\section{MATERIAL E MÉTODOS}

\subsection{Caracterização da Área de Estudo}

O estudo foi realizado no município de Botucatu, localizado na região centro-sul do Estado de São Paulo, distante $234 \mathrm{~km}$ da capital e está situada na zona $22 \mathrm{~S}$ entre as coordenadas planas e pelo Sistema de Projeção UTM (Universal Transversal de Mercator) 762290 L e 7468350 S. A sub-bacia do Córrego do Cintra está localizada no reverso da Cuesta Basáltica a noroeste da cidade de Botucatu (Souza et al., 2003), parte integrante da sub-bacia do rio Araquá e Bacia Hidrográfica do Tietê. O Córrego do Cintra nasce dentro do Campus da UNESP de Rubião Junior e segue seu fluxo ao norte até o rio Tietê (Gralhóz e Nogueira, 2006); está situada entre as coordenadas UTM (X) 754000 a 758000 e (Y) 7466000 a 7471000 , com uma área total de $1.136,8$ ha e altitude que varia de 851 a 741 metros da nascente à foz do córrego (Figura 1).

As condições de relevo, bastante diversas, e a posição geográfica, próximo ao Trópico de Capricórnio (sul do município), contribuem para dificultar o estabelecimento de um tipo climático padrão. Contudo, segundo classificação de Köppen, alguns autores classificam o clima como mesotérmico, atribuindo-lhe a designação de Cfa (chuvas relativamente abundantes e certas características de um regime litorâneo) (Souza et al., 2003). Para Tubelis et al. (1971) apud Souza et al. (2003), o regime de chuvas tem se mostrado variável, chegando a apresentar características continentais, o que sugeriria tipo climático tropical de altitude, identificado como Cwa. De acordo com Figueiroa (2008), as temperaturas médias anuais são em torno de $19^{\circ} \mathrm{C}$ e os índices pluviométricos médios ultrapassam $1.250 \mathrm{~mm}$.

A área de amostragem para análise florística foi estabelecida em três transecções do fragmento de mata nativa, ao longo do córrego do Cintra e principais tributários que apresentaram mata ripária mais representativa na sub-bacia. Foram demarcadas na parte inferior - sul (área $1=62,4 \mathrm{ha}$ ), na parte central (área $2=42,4 \mathrm{ha}$ ) e na parte superior - norte (área $3=30,7$ ha) (Figura 2). 


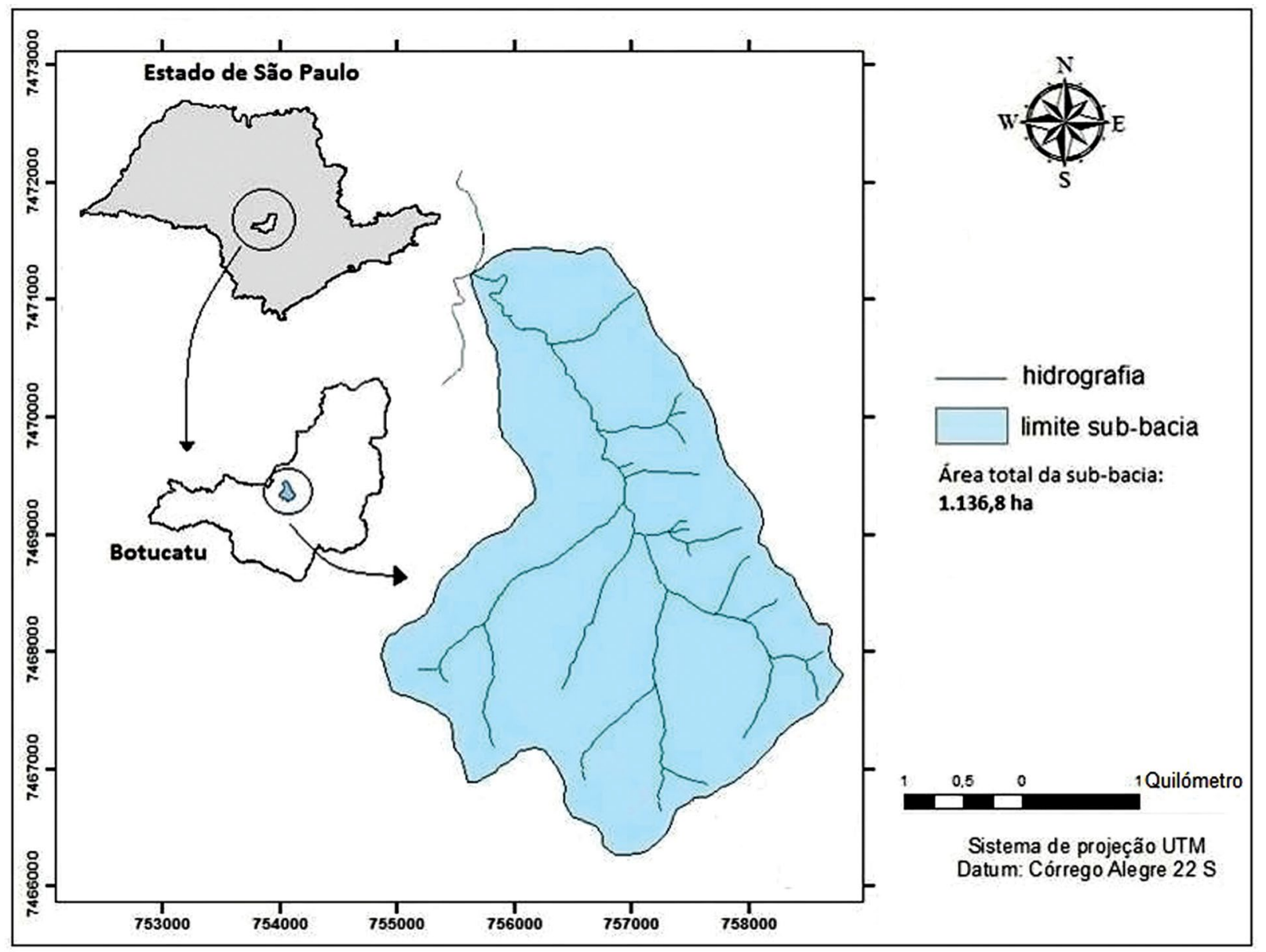

Figura 1. Localização da área da sub-bacia do córrego do Cintra e sua rede de drenagem.

Figure 1. Location of the sub-watershed of Cintra stream and its drainage system. 
BELLUTA, I. et al. Vegetação ripária do córrego Cintra, Botucatu - SP

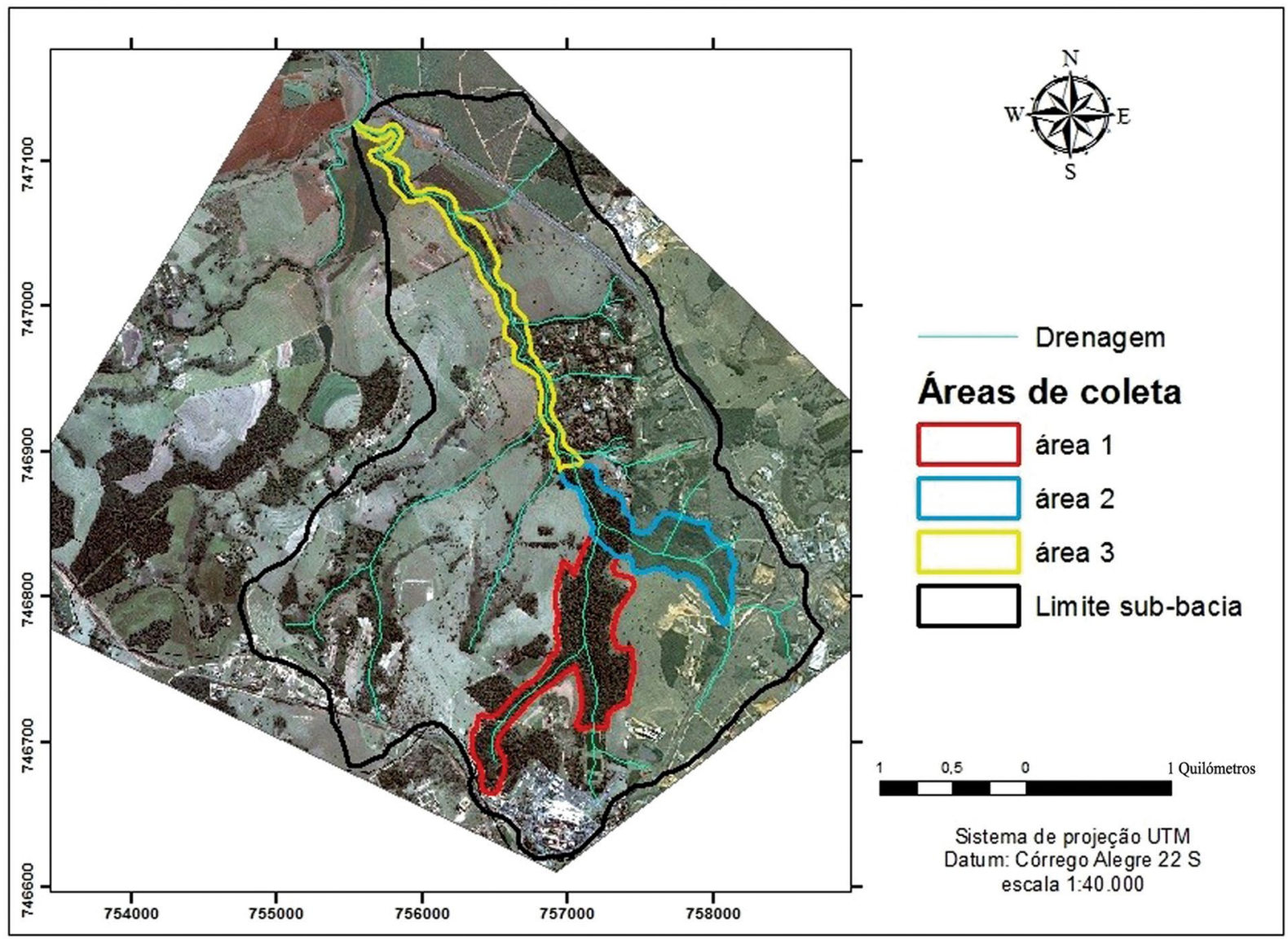

Figura 2. Áreas do levantamento florístico da sub-bacia do córrego do Cintra. Fonte: Belluta (2012).

Figure 2. Areas of floristic survey of the sub-watershed of Cintra stream. Source: Belluta (2012). 


\subsection{Estrutura da Vegetação}

Para avaliar a topossequência da Floresta Estacional Semidecidual - FES, foi utilizado o método de distâncias ou de ponto-quadrante (Cottam e Curtis, 1956 apud Moro e Martins, 2011).

Nas três áreas de estudo, apesar de possuir diferentes tamanhos, foram demarcados os pontos quadrantes paralelos e longitudinalmente às margens direita e esquerda ao longo do córrego, transectos lineares com pontos estabelecidos sistematicamente e equidistantes a cada $10 \mathrm{~m}$, tomando-se o cuidado para que o mesmo indivíduo não fosse computado duas vezes. Em cada ponto amostral, para a determinação dos quadrantes, foi utilizada uma cruzeta (4 quadrantes) de madeira, que foi girada aleatoriamente junto a uma estaca de madeira fixada no local do ponto pré-determinado. $\mathrm{O}$ critério de inclusão da amostragem em cada quadrante foi amostrar dois indivíduos (um superior e outro inferior a $5 \mathrm{~m}$ de altura) mais próximo do ponto amostral (Moro e Martins, 2011), sendo 8 indivíduos por ponto. $\mathrm{Na}$ área 1 , foram demarcados 168 pontos, na área 2, 86 pontos e na área 3, 21 pontos, totalizando 275 pontos.

Para a medição dos diâmetros foi utilizada uma suta de precisão e a altura foi estimada com o auxílio de uma vara graduada. Alguns indivíduos de espécies abundantes e bem conhecidas foram identificados no campo, por especialistas, enquanto os demais tiveram o material botânico coletado para posterior identificação. A herborização do material botânico foi feita no Laboratório de Ecologia Florestal do setor de Ciência Florestal/DRN, Engenharia Florestal da Faculdade de Ciências Agronômicas da Unesp Campus de Botucatu, Lageado. Os dados foram computados em planilha eletrônica.

Foram estimados os parâmetros densidade relativa - DR, dominância relativa - DoR e índice de valor de cobertura - IVC, obtidos da soma dos dois parâmetros relativos já citados (Mueller-Dombois e Ellenberg, 1974). A diversidadede espécies foi estudada com base nos índices de diversidade de Shannon-Wiener ( $\left.\mathrm{H}^{\prime}\right)$, Pielou (J) (equabilidade) e Simpson, conotação 1-D (Magurran, 2004), utilizando-se o programa Past.

Os espécimes amostrados no presente estudo foram identificados até o nível de espécie. Foram geradas tabelas fitossociológicas, com todas as espécies amostradas em ordem alfabética, tendo sido registrados ao lado a família a que pertencem, seus nomes comuns, os números de indivíduos amostrados, os parâmetros fitossociológicos (DR, DoR e IVC) e o grupo ecológico, segundo os autores acima citados. As espécies identificadas nos grupos sucessionais foram classificadas segundo seu estádio sucessional pioneiro, secundário inicial e secundário tardio, considerando-se mais de $50 \%$ os indivíduos de um estádio como determinante deste (Budowski, 1970 apud Madergan, 2006). Foram consideradas "espécies sem caracterização" aquelas sobre as quais não foram encontradas citações na literatura e as exóticas. Serviram de referência para a classificação das espécies nesses grupos ecológicos as informações contidas em Fonseca e Rodrigues (2000), São Paulo (2001), Cardoso-leite et al. (2004), Alcalá et al. (2006), Guaratini et al. (2008) e Cardoso-Leite e Rodrigues (2008).

Para a identificação do estádio de desenvolvimento de uma floresta, analisou-se a proporção relativa entre os números de indivíduos de espécies dos diferentes grupos. Esse procedimento foi adotado por Dislich et al. (2001) e Cardoso-Leite e Rodrigues (2008), de acordo com Budowski (1970) apud Martins (2009).

Para o tratamento estatísticos das espécies arbóreas encontradas nas três áreas distintas, como as variáveis não apresentaram distribuição normal e homogeneidade de variâncias, foram realizadas análises não paramétricas, ou seja, foi utilizado o teste de Friedman na comparação das mesmas (Sokal e Rohlf, 1995), seguidas do teste de Dunn, ao nível de 5\% de significância. 


\section{RESULTADOS E DISCUSSÃO}

Foram registrados 2.241 indivíduos arbóreos, de 145 espécies, pertencentes a 55 famílias botânicas na mata ripária da sub-bacia do córrego do Cintra. Das espécies estudadas, somente três são exóticas: Eucalyptus sp. (eucalipto) e Pinus elliottii (pinus), consideradas espécies arbóreas exóticas com alto grau de disseminação no Brasil (Santana e Encinas, 2008) e Psidium guajava (goiabeira), considerada espécie exótica extrabrasileira (América Central), e ocorrem espontaneamente em território brasileiro (Sampaio et al., 2011). Esta última, espécie frutífera (goiaba), está sendo usada para auxiliar na regeneração de Áreas de Preservação Permanentes - APP degradadas de acordo com a Resolução do CONAMA n ${ }^{\circ} 429$, artigo $5, \S 3^{\circ}$ (Brasil, 2011).
A Tabela 1 mostra a análise de variância do número de indivíduos - NI, a densidade relativa $-\mathrm{DR}$, dominância relativa - DoR e o índice de valor de cobertura (IVC), representados pelas letras minúsculas "a", "b" e "c" nas três áreas de estudo.

$\mathrm{Na}$ Figura $3 \mathrm{ABCD}$, o gráfico de caixas referente aos índices obtidos ilustra as diferenças entre as áreas de estudo observadas na Tabela 1 . O NI variou estatisticamente entre as áreas de acordo com as letras (A1 > A2 > A3), ou seja, a área 1 tem maior NI (1.381) com relação à área 2 (690) e este é menor à área 3 (170). A DR é similar estatisticamente nas áreas 1 e 2, mas diferente com relação à área 3 $(\mathrm{A} 1=\mathrm{A} 2>\mathrm{A} 3)$; a DoR apresentou-se similar nas áreas 2 e 3, com diferenças estatísticas com relação à área $1(\mathrm{~A} 1>\mathrm{A} 2=\mathrm{A} 3)$ e o IVC apresentou diferenças nas três áreas $(\mathrm{A} 1>\mathrm{A} 2>\mathrm{A} 3)$. As quatro variáveis apresentam medianas relativamente próximas, alta dispersão, e valores discrepantes.

Tabela 1 . Mediana, $1^{\circ}$ e $3^{\circ}$ quartil, entre colchetes, relativos às variáveis segundo a área.

Table 1 . Median, $1^{\text {st }}$ and $3^{\text {rd }}$ quartile, in brackets, relative to variables by area.

\begin{tabular}{lcccc}
\hline & Área 1 (62,4 ha) & Área 2 $(42,4 \mathrm{ha})$ & Área 3 $(30,7 \mathrm{ha})$ & Valor $\mathrm{p}$ \\
\hline NI & $3[1,10] \mathrm{a}$ & $1[0,3] \mathrm{b}$ & $0[0,1] \mathrm{c}$ & $<0,001$ \\
DR & $0,29[0,07 ; 0,80] \mathrm{a}$ & $0,14[0,00 ; 0,70] \mathrm{a}$ & $0,00[0,00 ; 0,61] \mathrm{b}$ & $<0,001$ \\
DoR & $0,100[0,008 ; 0,580] \mathrm{a}$ & $0,000[0,000 ; 0,392] \mathrm{b}$ & $0,000[0,000 ; 0,030] \mathrm{b}$ & $<0,001$ \\
IVC & $0,460[0,117 ; 1,507] \mathrm{a}$ & $0,150[0,000 ; 1,495] \mathrm{b}$ & $0,000[0,000 ; 0,755] \mathrm{c}$ & $<0,001$ \\
\hline
\end{tabular}

Letras minúsculas comparam áreas para cada variável. 

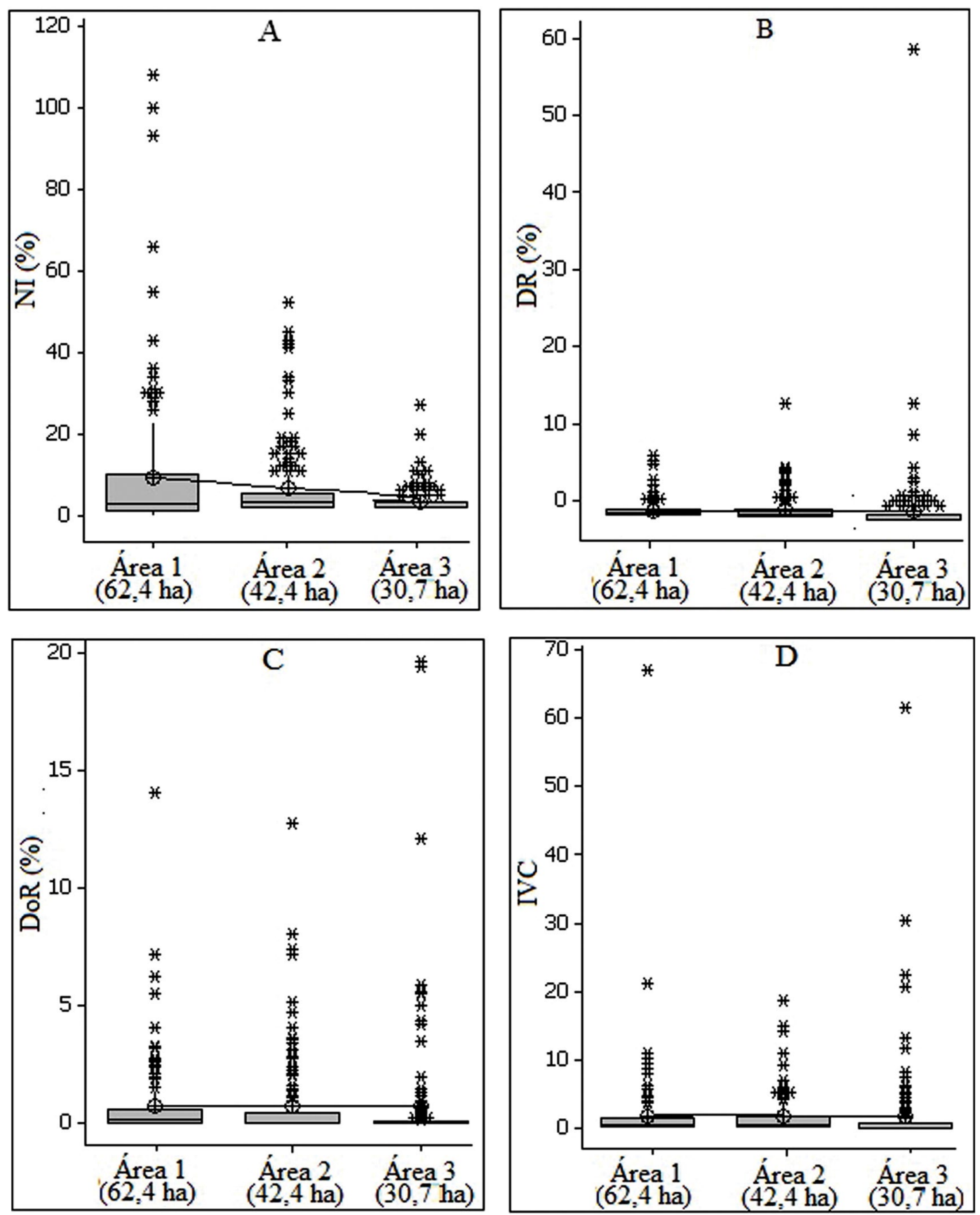

Figura 3. Gráficos de caixas, segundo a área, referentes ao NI (A), DR (B), DoR (C) e IVC (D).

Figure 3. Box plots by area related to NI (A), DR (B), DoR (C) and IVC (D). 
Na Figura 4 estão representadas as 10 primeiras famílias que mais contribuíram com maior riqueza de espécies. Nas áreas 1, 2 e 3, como um todo (135,5 ha), a família Fabaceae predominou em 16,3\%, além de Lauraceae, Myrtaceae e Boraginaceae (7,0\%), que juntas totalizaram 37,3\% da amostragem. Nos estudos de Biral e Lombardi (2012) e Gabriel (1990), na região da Cuesta de Botucatu, houve também o predomínio da família Fabaceae com maior número de espécies e em outros trabalhos citados no interior do Estado de São Paulo, pois tende a ser a principal família em levantamentos extensivos em FES.

$\mathrm{Na}$ área 1 (62,4 ha), separadamente, houve predomínio das famílias Fabaceae $(10,1 \%)$, com 113 indivíduos arbóreos; Myrtaceae (6,2\%); Lauraceae $(6,2 \%)$ e Meliaceae $(6,2 \%)$, que tiveram 46, 57 e 72 indivíduos, com 17, 9, 11 e 9 espécies, respectivamente. Nos estudos de Cerqueira et al. (2008), em quatro fragmentos de FES em Bragança Paulista (SP), e em mais 15 trabalhos realizados na região, foram encontrados padrões de semelhança com relação às famílias presentes nesta área. $\mathrm{Na}$ área 2 (42,4 ha) a família Fabaceae (13,6\%) apresentou
41 indivíduos arbóreos; as famílias Euphorbiaceae (5,7\%); Meliaceae (4,6\%), tiveram 46, 42, 29 e 5 indivíduos, com 5, 5, 4 e 3 espécies, respectivamente, do total da amostragem. Na área 3 (30,7 ha), mais uma vez a família Fabaceae predominou com 16,3\%, com 47 indivíduos e 7 espécies; as famílias Boraginaceae (7,0\%); Myrtaceae (7,0\%); Anacardiaceae $(4,7 \%)$ e Euphorbiaceae $(4,7 \%)$, as quais apresentaram 47, 14, 13, 12, 2 e 10 indivíduos, e com 7, 3, 3, 5, 2 e 3 espécies, respectivamente. Gabriel (1990), em seu estudo na Cuesta de Botucatu, encontrou diferenças na estrutura fitossociológica nos três diferentes compartimentos, de acordo com a altitude e relevo. Na parte superior (planalto) foi encontrado menor número de espécies (59) e famílias (31) em relação à intermediária (Front) com 65 e 35, respectivamente. A família Meliaceae destacou-se nesses dois compartimentos com a espécie Trichilia elegans (pau-ervilha). $\mathrm{Na}$ parte inferior (depressão periférica) foi encontrado o maior número de famílias (75) e espécies (38), cuja família mais abundante foi Meliaceae, com Trichilia clausseni a espécie mais abundante.
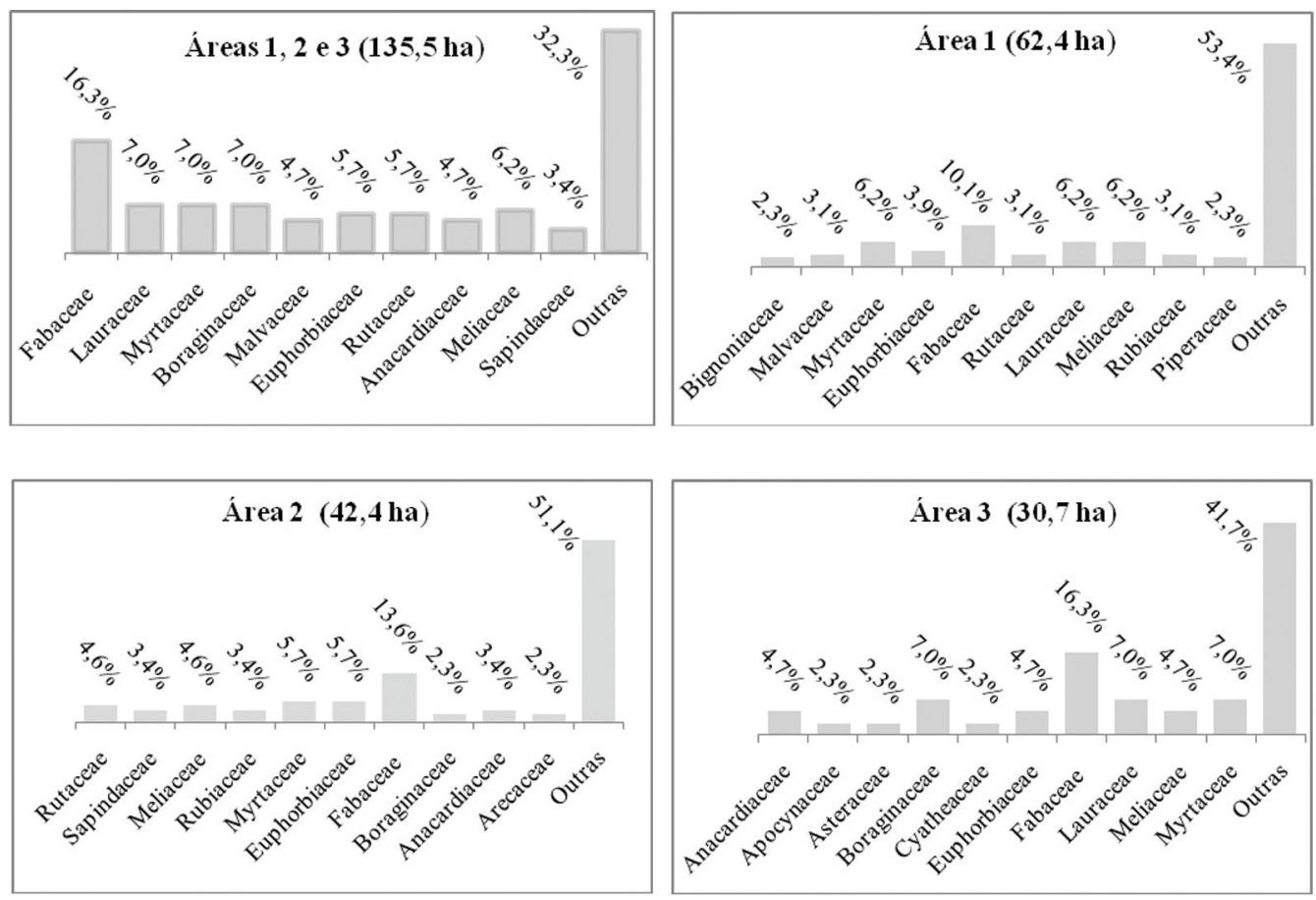

Figura 4. Porcentagem das 10 famílias com maior riqueza de espécies das três áreas como um todo (áreas 1,2 e 3 ) e por local de estudo: área 1 , área 2 e área 3.

Figure 4. Percentage of the 10 families with the highest species richness in the three areas as a whole (areas 1, 2 and 3) and per study site: area 1 , area 2 and area 3. 
As famílias em comum com maior riqueza entre as áreas 1 e 3 foram Fabaceae, com 26,4\% e Myrtaceae, Lauraceae, Meliaceae e Boraginaceae $(39,6 \%)$, pois tiveram 283 indivíduos, com 37 espécies e 58 indivíduos com 16 espécies, respectivamente, do total da amostragem. Desse modo, nas três áreas, entre as dez famílias, as mais representativas e as que se destacaram com maior riqueza de espécies em todas as áreas foram Fabaceae e Myrtaceae, semelhante aos resultados obtidos nos estudos realizados nas regiões de Cuestas Basálticas por Almeida-Scabbia et al. (2011), Teixeira e Rodrigues (2006) e Fonseca e Rodrigues (2000), entre outros trabalhos (Cerqueira et al., 2008; Bernacci et al., 2006) realizados em FES associada à matas ribeiras no interior do Estado de São Paulo.

Entre as espécies mais abundantes encontradas na área 1 (Tabela 2), a espécie Calophyllum brasiliense (guanandi), com indivíduos de até $21 \mathrm{~m}$ de altura, apresentou maior valor de cobertura $(21,3 \%)$ neste fragmento e foi a primeira espécie mais representativa, com 100 indivíduos e $10,65 \%$ do IVC total, principalmente pela alta DoR $(14,06 \%)$ apesar de sua reduzida DR (7,24\%). Isso significa que $14 \%$ de todos os indivíduos amostrados eram guanandi, e que esses representaram 21,3\% da área basal total de todos os indivíduos amostrados. Assim, o guanandi representou uma proporção maior da área basal, o que é um indicativo de ocupação da área de estudo, do que de abundância (número de indivíduos), pois deve possuir indivíduos maiores do que das outras espécies. De todos os trabalhos analisados em região de Cuesta, somente nos estudos de Teixeira e Rodrigues (2006), em Cristais Paulista, o guanandi foi encontrado. Esses autores citaram 23 trabalhos de diversas regiões do país, sendo que em $62 \%$ destes foi encontrado o guanandi em solos permanente ou periodicamente saturados hidricamente.

A segunda espécie, Protium heptaphyllum (almecegueira), também foi encontrada nos estudos em regiões de Cuesta. Particularmente, Teixeira e Rodrigues (2006) encontraram essa espécie em solos enxarcados e drenados, com até $19 \mathrm{~m}$ de altura e, IVC com 11,05, considerada a segunda espécie mais representativa com 108 indivíduos, com $5,52 \%$ do IVC total e está mais ligada à DR $(7,82 \%)$.

A espécie Pera glabrata (sapateiro), citada por Almeida-Scabbia et al. (2011) como pertencente à família Euphorbiaceae, com indívíduos de até $18,8 \mathrm{~m}$ de altura, foi a terceira espécie mais representativa com 66 indivíduos, que correspondem a $5,12 \%$ do IVC total, apresentou DR $(4,78 \%)$ e DoR $(5,48 \%)$ próximos entre si, mostrando uma proporção próxima entre a área basal total, que é um indicativo de ocupação da área de estudo, e a abundância (NI). As demais espécies na área 1 apresentaram quantidades gradativamente menores e significativas variações nos principais índices (Tabela 2).

$\mathrm{Na}$ área 2, a espécie Piptadenia gonoacantha (pau-jacaré) foi a primeira espécie mais representativa, com 40 indivíduos de até $23 \mathrm{~m}$ de altura. Essa espécie corresponde a $9,27 \%$ do IVC total, apresentou maior valor de cobertura $(18,55)$ nesse fragmento, principalmente pela alta DoR (12,75\%) e baixa DR $(5,8 \%)$, mostrando que $5,8 \%$ de todos os indivíduos amostrados eram de pau-jacaré, e que estes representaram $12,75 \%$ da área basal total de todos os indivíduos amostrados. Nectandra megapotamica (canelinha) foi a segunda espécie mais representativa, com 50 indivíduos e altura máxima de $20 \mathrm{~m}$ e 7,33\% do IVC total; apresentou DR $(7,25 \%)$ sensivelmente menor em relação à sua DoR $(7,4)$. A espécie Croton floribundus (capixingui) foi a terceira espécie mais representativa, com 41 indívíduos de até $15 \mathrm{~m}$ de altura; apresentou DoR mais alta $(8,04 \%)$ que a DR (5,94\%). Leite (2002) e SOSCuesta (2013) encontraram essa espécie liderando a lista de espécies com índices elevados de DR e DoR em área de Cuesta. As demais espécies na área 2 também apresentaram quantidades gradativamente menores e significativas variações nos principais índices (Tabela 2). 
BELLUTA, I. et al. Vegetação ripária do córrego Cintra, Botucatu - SP

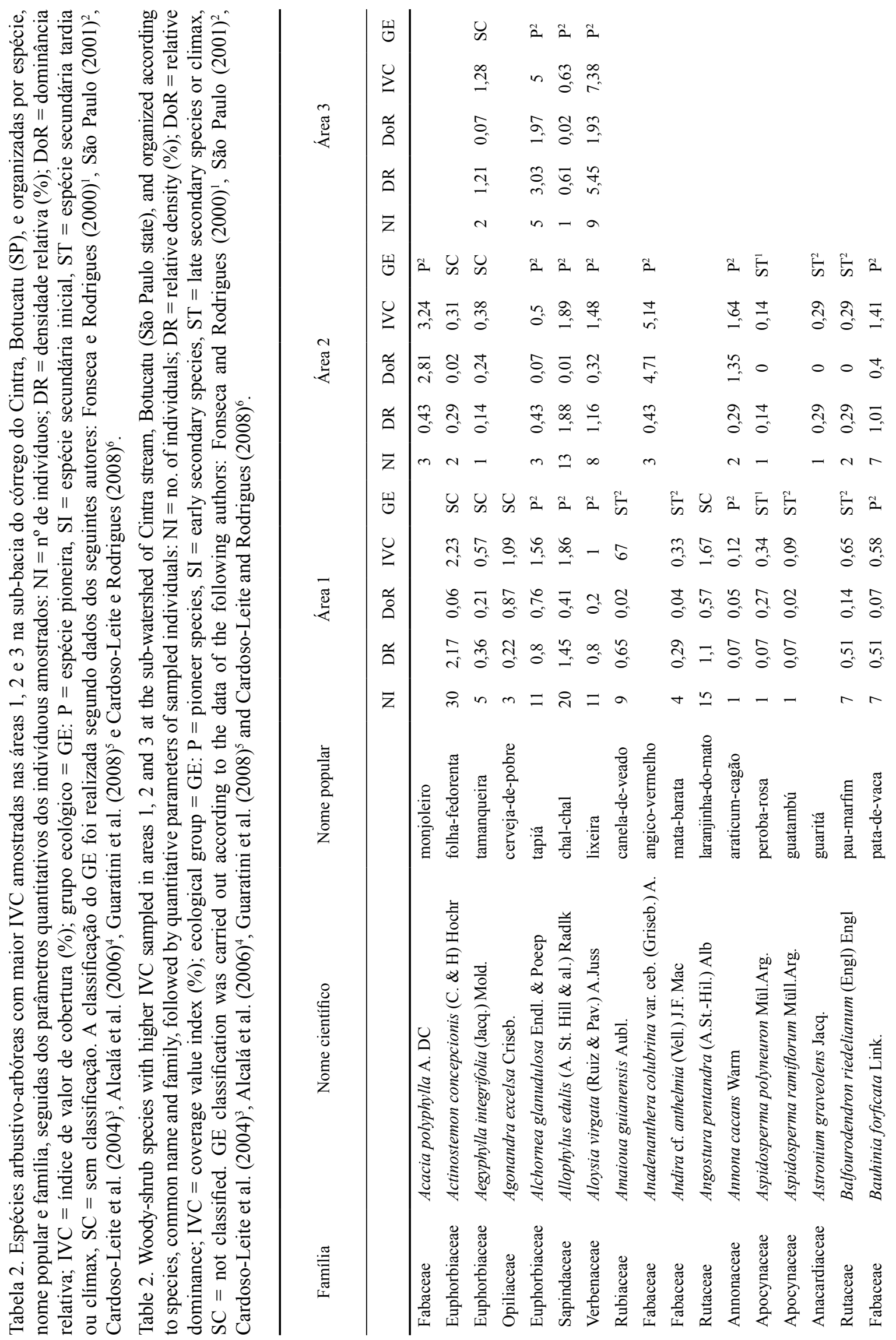




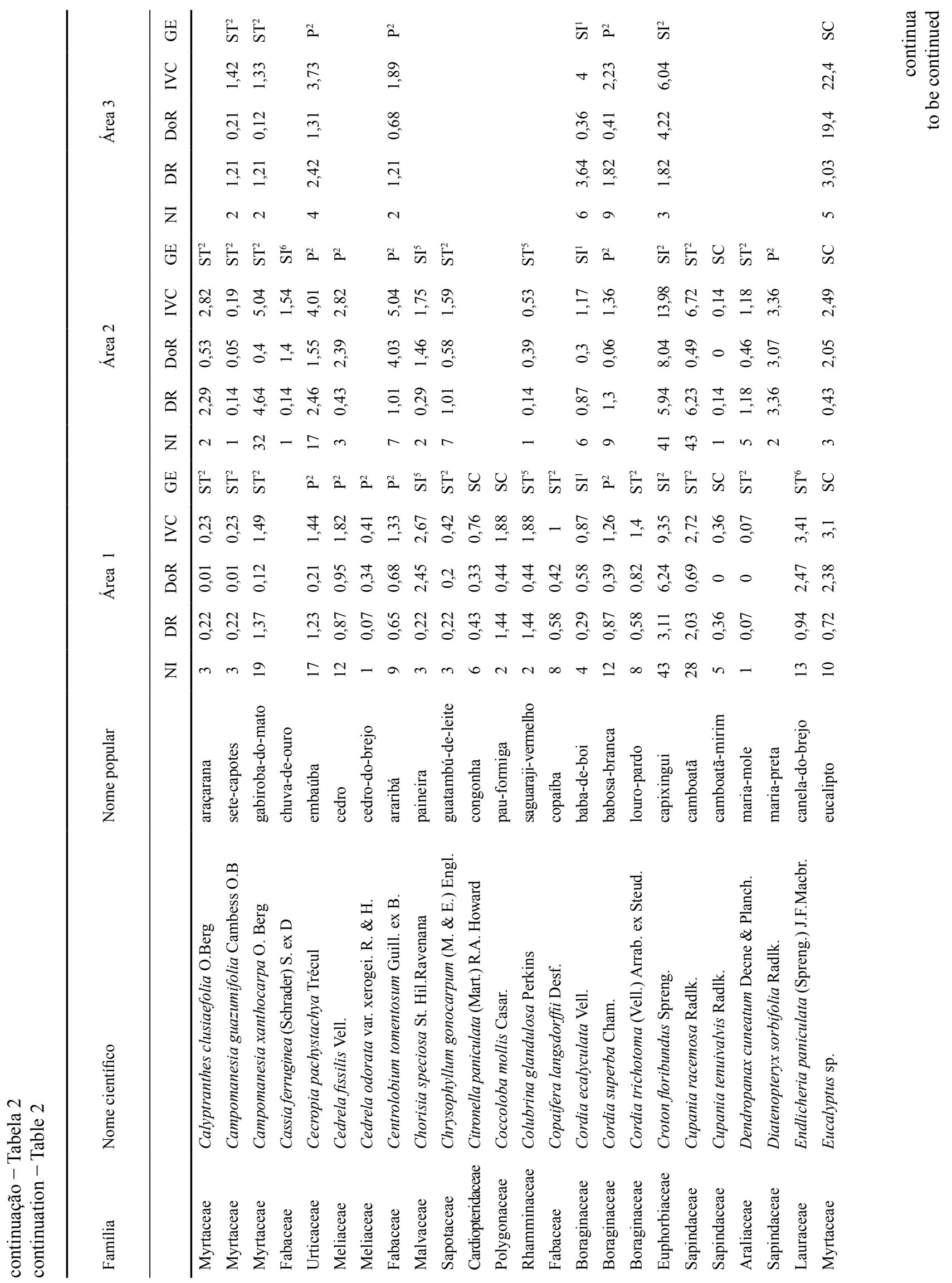


BELLUTA, I. et al. Vegetação ripária do córrego Cintra, Botucatu - SP

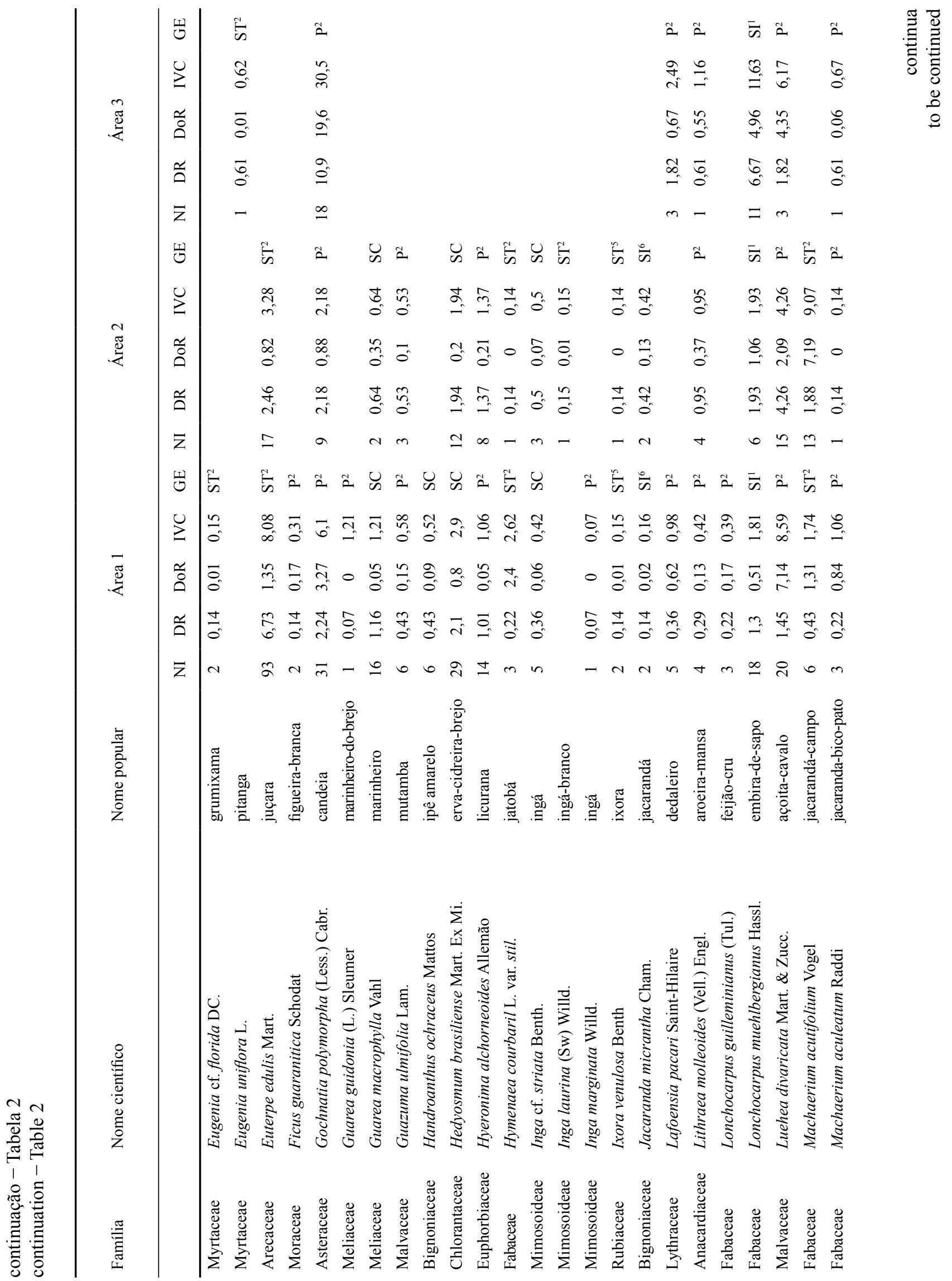




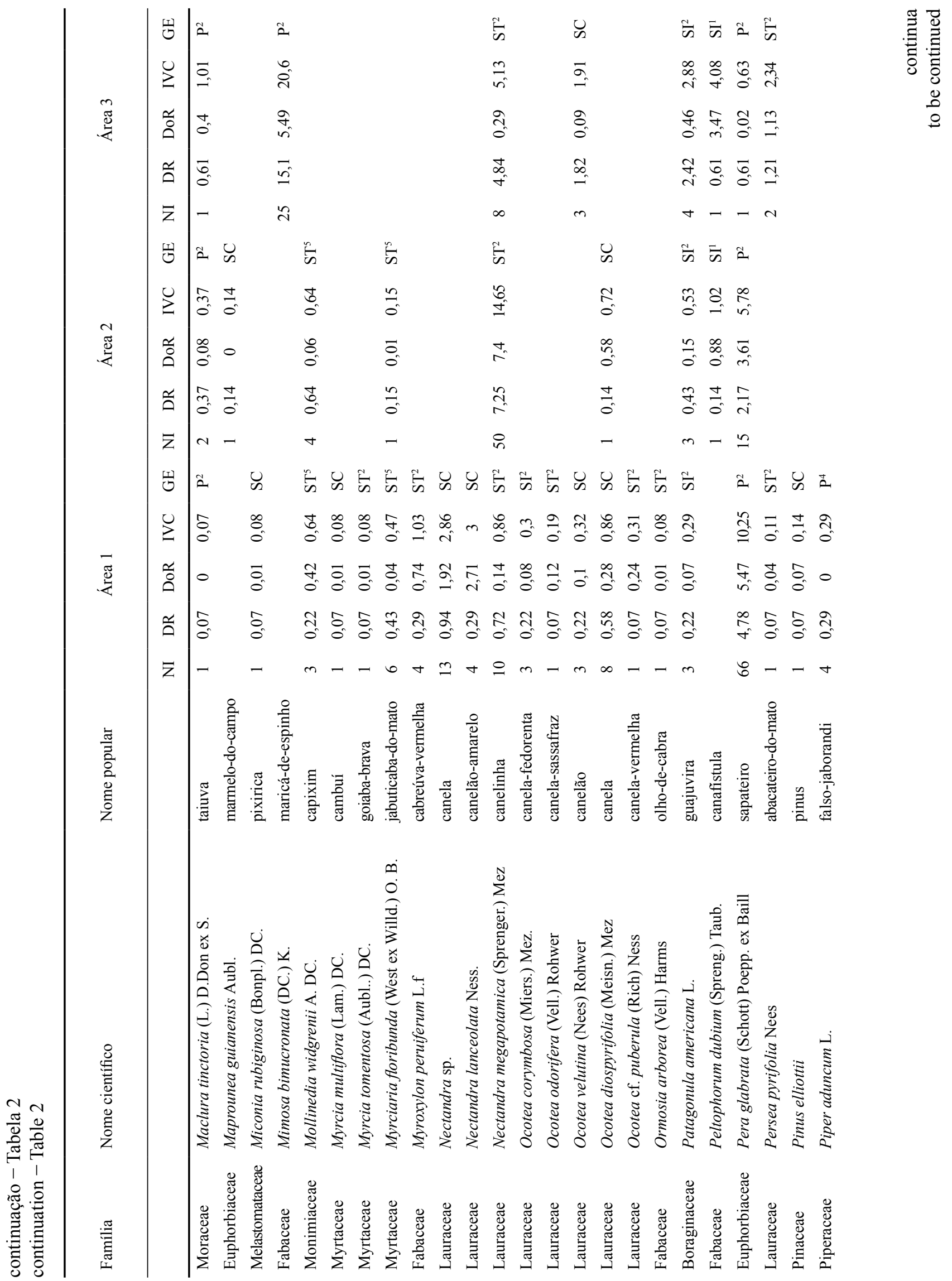


BELLUTA, I. et al. Vegetação ripária do córrego Cintra, Botucatu - SP

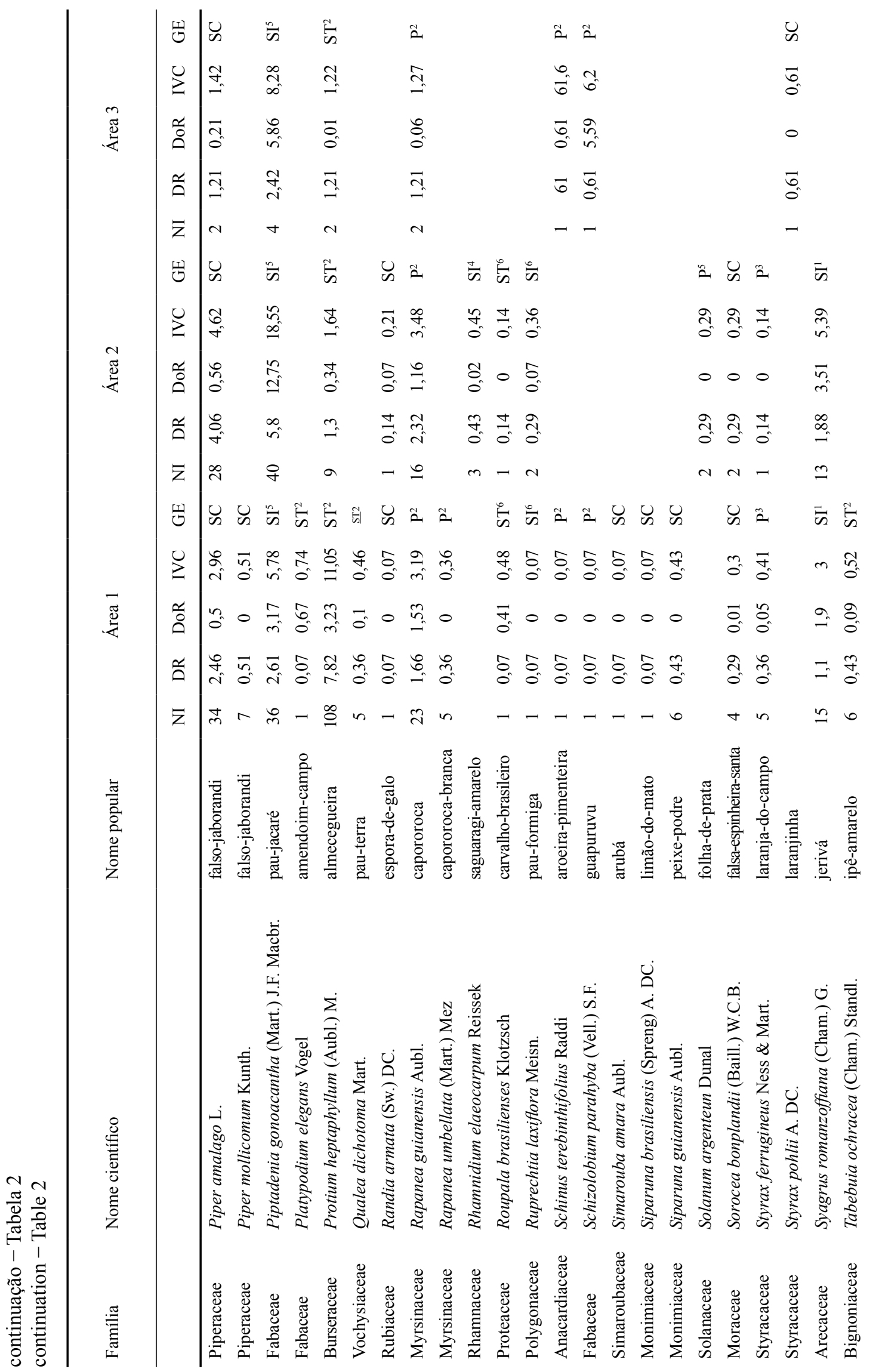




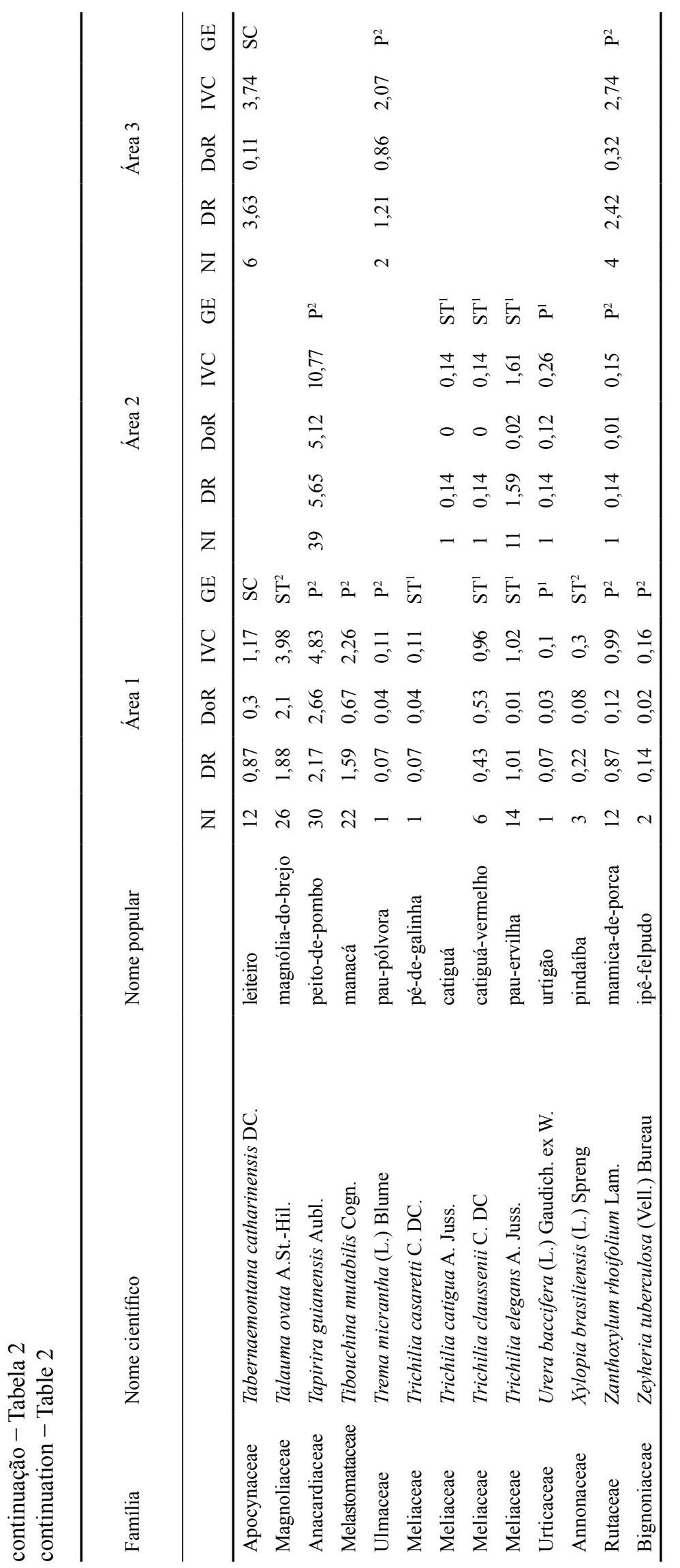


Na área 3, a espécie Gochnatia polymorpha (candeia) foi a primeira espécie mais representativa, com 18 indivíduos de até $9,5 \mathrm{~m}$ de altura; apresentou maior IVC $(30,53)$, que corresponde a $15,27 \%$ do total neste fragmento, principalmente pela alta DoR $(19,63 \%)$ e sua baixa DR $(10,9 \%)$, mostrando que $10,9 \%$ de todos os indivíduos amostrados eram de candeia, e que estes representaram 19,63\% da área basal total de todos os indivíduos amostrados. De acordo com Moro e Martins (2011), existem espécies que detêm porcentagem considerável de área basal total da comunidade, seja por possuírem muitos indivíduos ou por apresentar indivíduos de grande porte na área de estudo. A espécie Mimosa bimucronata (maricá-de-espinho), segunda espécie mais representativa nessa área, com indívíduos de até $9 \mathrm{~m}$ de altura, corresponde a 10,32\% do IVC total; apresentou também DR alta $(15,15 \%)$ em relação à DoR (5,49\%), ou seja, a maricá-de-espinho representou uma proporção menor daárea basal (que é um indicativo de ocupação de terreno) em relação à abundância (NI). A espécie Lonchocarpus muehlbergianus (embira-de-sapo) é a terceira espécie encontrada, com altura máxima de 9,7 m, correspondente a $5,82 \%$ do IVC total; apresentou também DR maior $(6,67 \%)$ em relação à sua DoR (4,96\%). As demais espécies na área 3 apresentaram quantidades gradativamente menores e significativas variações nos principais índices (Tabela 2 ).

Segundo Nascimento et al. (1999), as espécies que ocorrem em baixas DR são amplamente esparsadas, com pequenos tamanhos populacionais e sistema de cruzamento predominantemente exogâmico, com polinizadores voando a grandes distâncias, sendo mais suscetível à extinção local devido às variações ambientais, demográficas e catástrofes naturais. Assim, segundo o mesmo autor, com o isolamento populacional causado pela fragmentação, a imigração é um importante fenômeno para a manutenção de espécies de DR baixa de um determinado local. Caso não ocorra a imigração de novos propágulos, devido à presença de raras espécies, pode haver extinção nos pequenos fragmentos.

$\mathrm{Na}$ comparação das espécies entre as áreas estudadas, observaram-se 28 espécies comuns entre as três áreas, 54 estiveram presentes em duas das 3 áreas e, respectivamente, 46, 14 e 3 espécies ocorreram exclusivamente nas áreas 1,2 e 3. Assim, constatou-se que somente $19,32 \%$ das espécies amostradas foram comuns a todas as áreas,
$37,24 \%$ ocorreram em duas das três áreas e $43,44 \%$ ocorreram somente em uma das áreas amostradas. Entre as 20 espécies mais importantes e exclusivas de cada área amostral, ou seja, que não aparecem em outra, na área 1 foram encontradas as espécies Endlicheria paniculata (canela-do-brejo), Nectandra lanceolata (canelão-amarelo) e Talauma ovata (magnólia-do-brejo). $\mathrm{Na}$ área 2, a espécie Anadenanthera colubrina (angico-vermelho), e na área 3, Mimosa bimucronata (maricá-de-espinho).

Entre as três áreas de estudo, somente nas áreas 2 e 3 foi encontrado a espécie exótica Psidium guajava, devido ao fato de esta estar relacionada principalmente à amostragem ser realizada em área antropizada, próximo às chácaras e sede da propriedade. A mesma espécie foi encontrada nos estudos de Battilani et al. (2011), sugerindo invasão natural por parte das mesmas nas formações naturais, na região de estudo. Pinus elliottii, também espécie exótica, foi encontrada somente na área 1, diferente do Eucalyptus sp. encontrado nas três áreas, como ocorreu nos estudos de Silva (2010) e SOSCuesta (2013).

Os resultados obtidos referentes às três áreas amostrais indicam diferenças sucessionais em cada uma delas. A Figura 5 mostra a porcentagem das espécies dos grupos sucessionais amostrados nas áreas de estudo. Na Tabela 2 está apresentado o grupo ecológico (última coluna) de cada espécie amostrada, de acordo com as metodologias aplicadas por vários autores. Pôde-se observar que houve predomínio, nas três áreas como um todo, de espécies secundárias tardias $(36,6 \%)$ e pioneiras $(29,0 \%)$, ou seja, mais de $50 \%$ dos indivíduos pertenceram a estes grupos sucessionais. Assim, os fragmentos amostrados podem ser considerados em nível intermediário de sucessão, entre jovem a maduro, o que indica que sofreram perturbações recentes, devido à presença das pioneiras e das secundárias iniciais. Guaratini et al. (2008) verificaram que na FES, tanto os distúrbios de origem natural quanto antrópicos (retirada seletiva de espécies arbóreas) determinaram o aparecimento de espécies de estádios intermediários, fundamentados na deciduidade sazonal do dossel da floresta e perturbações antrópicas. De acordo com Martins (2009), as espécies pioneiras e secundárias iniciais não toleram sombreamento e possuem baixa longevidade, sendo encontradas em clareiras naturais, matas ciliares e em clareiras antrópicas; as secundárias tardias toleram o sombreamento apenas na fase jovem, e as clímax típicas de sub-bosques são tolerantes à sombra em todas as fases do ciclo da vida. 

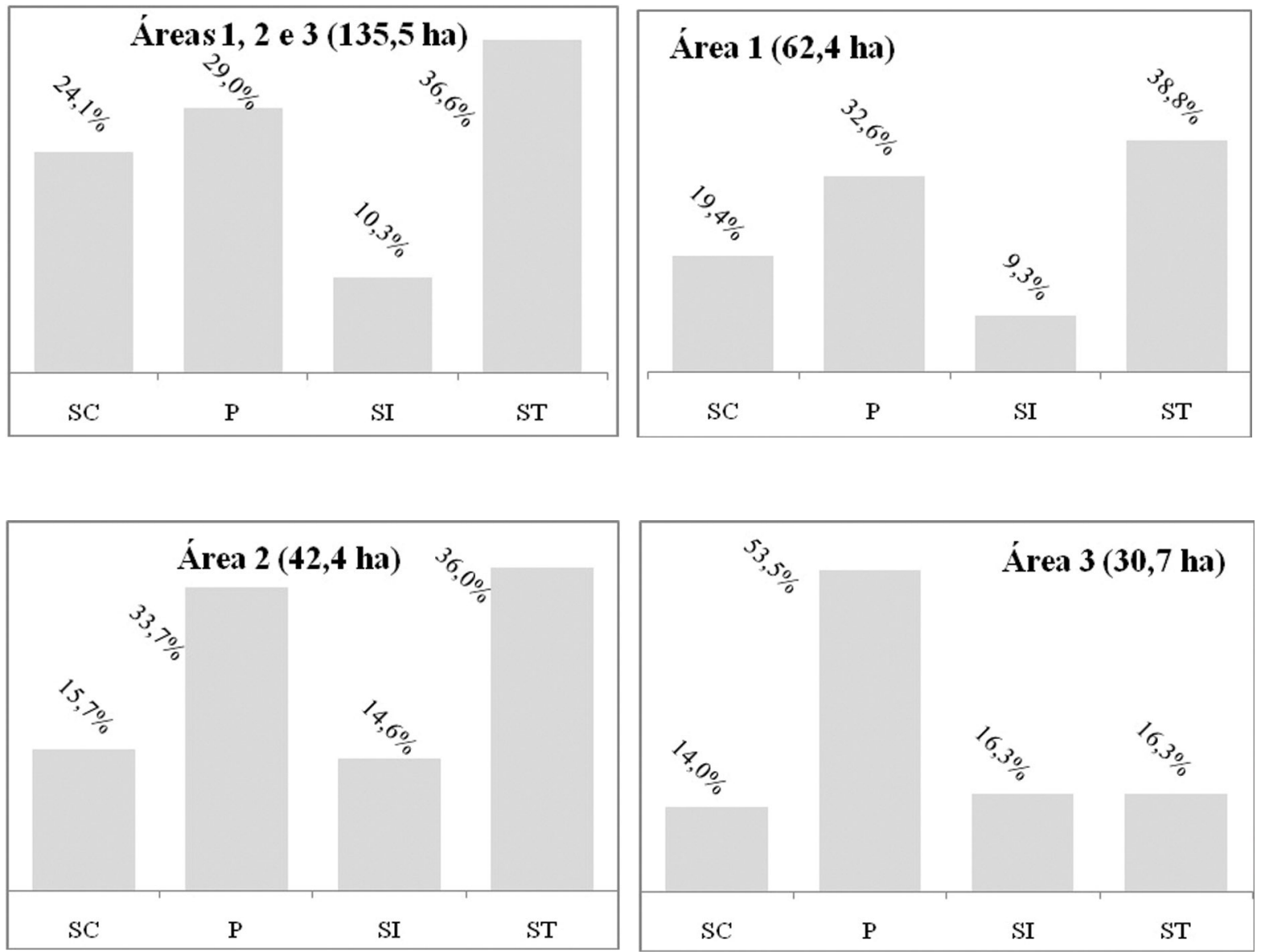

Figura 5. Porcentagem das espécies dos diferentes estádios sucessionais amostrados das três áreas como um todo (áreas 1, 2 e 3) e por local de estudo (área 1, área 2 e área 3) do fragmento de mata da sub-bacia do córrego do Cintra. $\mathrm{P}=$ pioneiras; $\mathrm{SI}=$ secundárias iniciais; $\mathrm{ST}=$ secundárias tardias e $\mathrm{SC}=$ sem caracterização.

Figure 5. Percentage of species of different successional stages sampled in the three areas as a whole (areas 1,2 and 3) and per study site (area 1, area 2 and area 3) of the forest fragment of the sub-watershed of Cintra stream. $\mathrm{P}=$ pioneer; $\mathrm{SI}=$ early secondary; $\mathrm{ST}=$ late secondary, and $\mathrm{SC}=$ not characterized.

Assim, a classificação em grupos sucessionais fundamenta-se no conhecimento prévio da regeneração dessas espécies em diferentes nichos.

De acordo com a Figura 5, ocorre a predominância das espécies consideradas secundárias tardias e reduzida quantidade de pioneiras nas áreas 1 e 2 com relação à área 3 . O mesmo ocorreu nos estudos de Guaratini et al (2008), pois cerca de $70 \%$ das espécies ocuparam estádios finais de sucessão, aliados às áreas perturbadas, ocupadas por espécies iniciais de sucessão. Esta projeção pode ser observada na Figura 2, que mostra a fitofisionomia densa através de imagem aérea de 2008, a preservação e manutenção dos limites das APPs. Nos estudos de Ivanauskas et al. (1999), na região de Cuesta (Itatinga), as espécies arbóreo-arbustivas mostraram que houve o predomínio de espécies iniciais (pioneira $-5 \%$ e secundária inicial $-41 \%$ ) e menor percentagem de espécies secundárias tardias $-33 \%$, o que indica ao estágio inicial de regeneração. 
Também na região da Cuesta, no Jardim Botânico do Instituto de Biociências (UNESP/Campus de Botucatu), parte integrante da cabeceira da sub-bacia do Cintra com fragmentos de FES, as espécies pioneiras predominaram nas áreas representando cerca de $40 \%$ das espécies classificadas, enquanto as secundárias iniciais e secundárias tardias ocorreram ambas com cerca de 30\% das espécies (Silva, 2010). Nos estudos de Cassola (2008), também em região de Cuesta, ocorreu o predomínio das espécies iniciais de regeneração, ou seja, espécies em condição jovem.
$\mathrm{Na}$ área 1, a dominância das espécies com estádio sucessional tardia e a pioneira (mesmo somado ao secundário inicial) não superaram $50 \%$, mas pode ser considerado entre as duas classes. O mesmo ocorre na Figura 6, quando o percentual das espécies é inferior a $50 \%$ nos estádios secundários tardios, destacandose com maior número de indivíduos $(43,3 \%)$, indica ser estádio mais avançado de sucessão em relação às pioneiras. A Tabela 2 mostra a lista das espécies encontradas nas três áreas, nos diferentes grupos ecológicos.
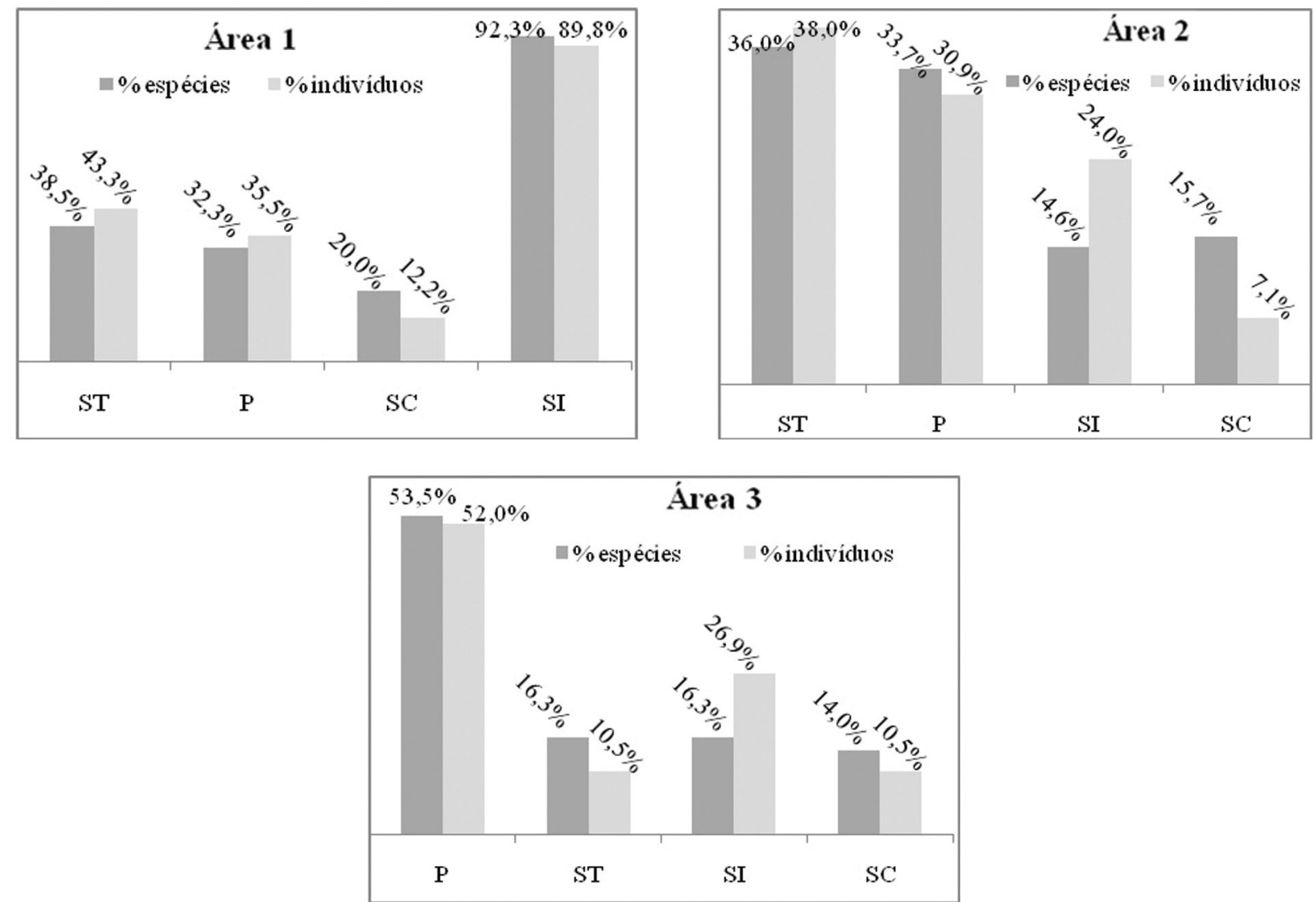

Figura 6. Comparação entre a porcentagem de espécies e indivíduos distribuídos em classes sucessionais das áreas 1, 2 e 3 da sub-bacia do córrego do Cintra. $\mathrm{P}=$ pioneiras; $\mathrm{SI}=$ secundárias iniciais; $\mathrm{ST}=$ secundárias tardias e $\mathrm{SC}=$ sem caracterização.

Figure 6. Comparison between percentage of species and individuals distributed into successional classes in areas 1,2 and 3 of the sub-watershed of Cintra stream. $\mathrm{P}=$ pioneer; $\mathrm{SI}=$ early secondary; $\mathrm{ST}=$ late secondary, and $\mathrm{SC}=$ not characterized. 
Da mesma forma como ocorreu na área 1 , na área 2 as espécies dos estádios sucessionais tardia e a pioneira (mesmo somados à secundária inicial) também não superaram $50 \%$. Poderíamos considerá-lo como estádio mais avançado de sucessão (secundária inicial), se somássemos o número de indivíduos dos estádios secundário inicial e primária, pois obteríamos o número superior a $50 \%$, apesar de porcentuais baixos entre suas espécies nos dois estádios. Diferente disso, nos estudos na Mata da Câmara (FES), em São Roque, Cardoso-Leite e Rodrigues (2008) observaram que a dominância de poucas espécies indicou perturbações na área de estudo, evidenciando uma floresta em estádio de sucessão inicial.

$\mathrm{Na}$ área 3 (Figura 6), 13 foram pioneiras, quatro secundárias iniciais, uma sem classificação e somente duas foram consideradas tardias, o que demonstra predomínio das pioneiras com o número de indivíduos superior a 50\%. Essa área apresenta estádio inicial de sucessão dominante e número reduzido de secundárias tardias.
Em se tratando da dominância de espécies pioneiras, estudos realizados por Rodrigues e Gandolfi (2001) recomendam que sejam utilizadas, no enriquecimento e reflorestamento dessas áreas, as espécies secundárias tardias.

Quanto à diversidade, o índice de Shannon (H') das espécies encontradas na área $1(4,078)$ é maior em relação às áreas 2 e 3 (Tabela 3). Essas diferenças podem ser atribuídas às dimensões das áreas de amostragem e à riqueza de espécies entre uma área e outra, bem como a equidade de cada uma. Os valores da diversidade estão dentro da faixa de variação para os fragmentos da FES da região de Botucatu (SOSCuesta, 2013; Gabriel (2009); Teixeira e Rodrigues (2006); Silva e Soares (2003); Leite (2002) e Ivanauskas et al. (1999)), variaram de 3,2 a 4,2, cujos valores estão próximos das áreas do presente estudo. Em Itirapina, em região de Cuesta, região de São Carlos, o valor de $H^{\prime}$ também esteve nessa faixa (Kotchetkoff-Henriques e Joly (1994).

Tabela 3. Distribuição do número de espécies, indivíduos e Índices de Diversidade florística nos locais de estudos.

Table 3. Distribution of the number of species, individuals and floristic Diversity Indexes at the study sites.

\begin{tabular}{|c|c|c|c|c|}
\hline & & \multicolumn{3}{|c|}{ Local } \\
\hline & & $\begin{array}{c}\text { área } 1 \\
(62,4 \text { ha) }\end{array}$ & $\begin{array}{c}\text { área } 2 \\
(42,4 \text { ha })\end{array}$ & $\begin{array}{c}\text { área } 3 \\
(30,7 \text { ha })\end{array}$ \\
\hline & $\mathrm{N}^{\mathrm{o}}$ de espécies & 129 & 88 & 43 \\
\hline \multirow[t]{3}{*}{ Dados gerais } & $\mathrm{N}^{\mathrm{o}}$ de indivíduos & 1380 & 690 & 171 \\
\hline & $\mathrm{N}^{\mathrm{o}}$ de pontos amostrais & 173 & 86 & 21 \\
\hline & Shannon (H') & 4,078 & 3,796 & 3,313 \\
\hline \multirow[t]{2}{*}{ Índice de Diversidade } & Pielou ou Equabilidade (J) & 0,8391 & 0,8477 & 0,8808 \\
\hline & Simpson & 0,9712 & 0,9668 & 0,9452 \\
\hline
\end{tabular}


Segundo Cerqueira et al. (2008) e Madergan (2006), fatores ambientais, climáticos e geográficos dos fragmentos podem influenciar na similaridade entre levantamentos florísticos. Entretanto, esses índices levam em conta apenas a presença ou ausência das espécies nas áreas de estudo distribuídas na Tabela 2, e não sua abundância em cada área. As áreas 1 e 2, conforme a Figura 2, apesar de se apresentarem em conectividade e mata densa, houve influência de pastos sobre a mata. $\mathrm{O}$ valor mais baixo obtido no presente estudo $\left(\mathrm{H}^{\prime}=3,313\right.$ nats/ind $\left.{ }^{-1}\right)$, na área 3, quando comparado ao de outras florestas ripárias, justifica em parte pela sua dimensão, e pela localização (mata de várzea) e histórico de fragmentação. A similaridade florística em estudo pioneiro na região foi também baixa entre os fragmentos do Jardim Botânico da Unesp de Botucatu e Mata do Butignoli, localizado na cabeceira da sub-bacia do Cintra, e no Morro de Rubião Júnior, situado na sub-bacia do córrego da Cascata, adjacente ao do Cintra (Silva, 2010).

Os índices de Shannon (H'), Pielou ou Equabilidade (J) e de Simpson são considerados altos em todas as áreas quando comparados a outros estudos realizados em FES. Os valores entre 0,9452 e 0,9712 (Simpson) e 0,8391 e 0,8808 (Pielou) significam o quanto a diversidade representa em relação à máxima possível para o número de espécies existentes em cada área, onde os valores podem variar entre 0 e 1 . Então, nas áreas estudadas, considerando-se a notação D-1 para o índice de Simpson, quanto mais próximo de 1, maior é a diversidade. Assim, os resultados se apresentaram altos indicando que quase todas as espécies estão igualmente representadas ou distribuídas pelo número de indivíduos (baixa dominância), possibilitando inferir que existe uma distribuição homogênea entre ambos. Certamente, os valores de equidade poderiam ser diferentes se fosse aumentada a intensidade amostral, número de pontos amostrais nas três áreas.
O tamanho da área amostral utilizada, não significa, contudo, que tais espécies sejam naturalmente raras, mas que apresentam poucos indivíduos por unidade de área. $\mathrm{O}$ índice de Pielou (J) indica a relação entre a diversidade encontrada e a máxima possível para aquele número de espécies. Desse modo, os valores encontrados neste estudo também foram altos. Nos estudos em regiões de Cuesta, Cassola (2008), Teixeira e Rodrigues (2006) e Ivanauskas et al. (1999) apresentaram equabilidade na faixa de 0,77 a 0,84 , inferior aos índices obtidos no presente estudo.

Através da análise de caracterização fitossociológica das áreas estudadas, apesar de estarem próximas geograficamente e haver conectividade entre si (Figura 2), observou-se que a área 3 se apresenta mais fragmentada com relação às áreas 1 e 2, com o menor número de espécies, baixa densidade e riqueza de espécies, além de apresentar estádio sucessional inicial, provocado pela perturbação antrópica.

No estudo da composição florística, as espécies identificadas são importantes para auxiliar na recomposição por espécies apropriadas para a revegetação de áreas degradadas. De acordo com Ferreira e Dias (2004), nessas áreas, sugere-se um modelo sucessional que se baseia na combinação de espécies de diferentes grupos ecológicos ou categorias sucessionais. A utilização de espécies de início de sucessão, intolerantes à sombra e de crescimento rápido, já citado por Martins (2009), deve fornecer condições ecológicas, principalmente sombreamento, favoráveis ao desenvolvimento de espécies finais de sucessão (tardio). Nos estudos de Biral e Lombardi (2012), na região da Cuesta de Botucatu (Pavuna), para algumas espécies tanto a deciduidade foliar como o relevo da Cuesta favorecem a incidência luminosa até os estratos inferiores da comunidade, o que contribui também para a riqueza das espécies herbáceas. 
De acordo com a resolução que dá orientação para o reflorestamento heterogênio de áreas degradadas (Brasil, 2008), no seu artigo $6^{\circ}$, parágrafos $1^{\circ}$ e $2^{\circ}$, as espécies escolhidas deverão contemplar os dois Grupos Ecológicos pioneiros (P e SI) e não pioneiros (ST e Climácicas), considerando o limite mínimo de $40 \%$, para qualquer dos grupos. As espécies pertencentes a um mesmo GE, não pode exceder $60 \%$ do total de indivíduos e nenhuma espécie pioneira pode ultrapassar o limite máximo de $10 \%$ de indivíduos do total do plantio.

\section{CONCLUSÃO}

Em se tratando de um trabalho descritivo, os resultados mostraram haver uma diferenciação clara no grau de conservação e estádio sucessional dos fragmentos estudados, indicando a existência de fatores de degradação distintos que se refletem na estrutura da vegetação. A área 3 foi a mais afetada pela ação antrópica $\mathrm{e}$ necessita ser revegetada ou regenerada por espécies nativas. Comparando os resultados obtidos com trabalhos em fragmentos de FES na região de Botucatu e em outras regiões de Cuesta, observou-se níveis de degradação e riqueza de espécies semelhantes.

\section{REFERÊNCIAS BILBIOGRÁFICAS}

ALCALÁ, M.; FRANCESCHI, N.C.S.; STRANGHETTI, V. Florística de trechos de matas ciliares do ribeirão Borá e ribeirão Cubatão, Potirendaba-SP. Revista do Instituto Florestal, v. 18, p. 79-93, 2006.
ALMEIDA-SCABBIA, R.J. et al. Características físico-químicas do solo e distribuição de espécies arbóreas em um trecho de cuesta basáltica, Analândia, SP, Brasil. Revista Brasileira de Biociências, v. 9, n. 3, p. 322-331, 2011.

BERNACCI, L.C. et al. O efeito da fragmentação florestal na composição e riqueza de árvores na região da Reserva Morro Grande (planalto de Ibiúna, SP). Revista do Instituto Florestal, v. 18, n. 1, p. 121-166, 2006.

BIRAL, L.; LOMBARDI, J.A. Flora vascular da mata da Pavuna, Botucatu, SP, Brasil. Rodriguésia, v. 63, n. 2, p. 441-450, 2012.

BRASIL. Ministério do Meio Ambiente. Resolução CONAMA n. 429, de 28 de fevereiro de 2011. Dispõe sobre a metodologia de recuperação das Áreas de Preservação Permanente - APPs. Disponível em: <http://www.mma.gov.br/port/conama/>. Acesso em: 10 out. 2012.

BUDOWSKI, G. The distinction between old secondary and climax species in tropical Central American lowland rainforest. Tropical Ecology, v. 11, p. $44-48,1970$.

CARDOSO-LEITE, E. et al. Fitossociologia e caracterização sucessional de um fragmento de mata ciliar, em Rio Claro/SP, como subsídio à recuperação da área. Revista do Instituto Florestal, v. 16, n. 1, p. 31-41, 2004.

.; RODRIGUES, R.R. Fitossociologia e caracterização sucessional de um fragmento de floresta estacional no sudeste do Brasil. Revista Árvore, v. 32, n. 3, p. 583-595, 2008.

CASSOLA, H. Aspecto da estrutura fitossociológica e silvigenética em fragmentos de Floresta Estacional Semidecídua com diferentes histórias de perturbação em Botucatu-SP. 2008. 85 f. Dissertação (Mestrado em Conservação de Ecossistemas Florestais) - Escola Superior de Agricultura "Luiz de Queiroz", Piracicaba. 
CERQUEIRA, R.M.; GIL, A.S.B.; MEIRELES, L.D. Florística das espécies arbóreas de quatro fragmentos de Floresta Estacional Semidecídua Montana na fazenda Dona Carolina (Itatiba/ Bragança Paulista, São Paulo, Brasil). Revista do Instituto Florestal, v. 20, n. 1, p. 33-49, 2008.

COTTAM, G.; CURTIS, J.T. The use of distance measures in phytosociological sampling. Ecology, v. 37, n. 3, p. 451-460, 1956.

DISLICH, R.; CERSÓSIMO, L.; MANTOVANI, W. Análise da estrutura de fragmentos florestais no Planalto Paulistano-SP. Revista Brasileira de Botânica, v. 24, n. 3, p. 321-332, 2001.

FERREIRA, D.A.C.; DIAS, H.C.T. Situação atual da mata ciliar do ribeirão São Bartolomeu em Viçosa, MG. Rev. Árvore, v. 28, n. 4, p. 617-623, 2004.

FIGUEIROA, J.C. Botucatu: cidade dos bons ares e das boas escolas. São Paulo: Noovha América, 2008. $200 \mathrm{p}$.

FONSECA, R.C.B.; RODRIGUES, R.R. Análise estrutural e aspecto do mosaico sucessional de uma floresta semidecídua em Botucatu-SP. Scientia Florestalis, n. 57, p. 27-43, 2000.

GABRIEL, J.L.C. Composição florística e estrutura fitossociológica do estrato arbóreo de mata mesófila semidecídua de encosta, no município de Botucatu, SP. 1990. 198 f. Dissertação (Mestrado em Ciências Biológicas) Instituto de Biociências, Universidade Estadual Paulista, Rio Claro.

GRALHÓZ, G.; NOGUEIRA, M.G. Eutrofização e contaminação crônica de um riacho de Cuesta (Córrego do Cintra) e avaliação do sistema de tratamento de esgotos. São Carlos: Instituto Internacional de Ecologia e Gerenciamento Ambiental; Academia Brasileira de Ciências; Conselho Nacional de Desenvolvimento Científico e Tecnológico, 2006. p. 119-140.
GUARATINI, M.T.G. et al. Composição florística da Reserva Municipal de Santa Genebra, Campinas SP. Revista Brasileira de Botânica, v. 31, n. 2, p. 323-337, 2008.

IVANAUSKAS， N.M.; RODRIGUES， R.R.; NAVE, A.G. Fitossociologia de um trecho de Floresta Estacional Semidecidual em Itatinga, São Paulo, Brasil. Scientia Florestalis, n. 56, p. 83-99, 1999.

.; MONTEIRO, R.; RODRIGUES, R.R. Classificação fitogeográfica das florestas do Rio Alto Xingu. Acta Amazônica, v. 38, n. 3, p. 387-402, 2008.

KOTCHETKOFF-HENRIQUES, O; JOLY, C.A. Estudo florístico e fitossociológico em uma mata mesófila semidecídua da Serra do Itaqueri, Itirapina, Estado de São Paulo, Brasil. Revista Brasileira de Biologia, v. 54, n. 3, p. 477-487, 1994.

LEITE, S.S. Análise ambiental da área do Morro do Cuscuzeiro (Analândia) como subsídio ao planejamento do ambiente local. 2002. $161 \mathrm{f}$. Dissertação (Mestrado em Ecologia e Recursos Naturais) - Centro de Ciências Biológicas e da Saúde, Universidade Federal de São Carlos, São Carlos.

MADERGAN, C.M. Estádio sucessional e estrutura fitossociológica de um fragmento de vegetação florestal existente às margens do rio Dourado em Guaiçara, SP. 2006. 85 f. Dissertação (Mestrado em Botânica) - Instituto de Biociências, Universidade Estadual Paulista, Botucatu. 
MAGURRAN, A.E. Measuring biological diversity. Victoria: Blackwell, 2004. 256 p.

\section{MARTINS, S.V. Ecologia de florestas tropicais} do Brasil. Viçosa, MG: UFV, 2009. 261 p.

MORO, M.F.; MARTINS, F.R. Método de levantamento do componente arbóreo-arbustivo. In: FELFILI, J.M. et al. Fitossociologia do Brasil: métodos e estudos de casos. 6. ed. Viçosa, MG: UFV, 2011. cap. 6, p. 174-212.

MUELLER-DOMBOIS, D.; ELLENBERG, H. Aims and methods of vegetation ecology. New York: John Wiley, 1974. 547 p.

NASCIMENTO, H.E.M. et al. Estrutura e dinânica de populações arbóreas de um fragmento de Floresta Estacional Semidecidual na região de Piracicaba. Revista Brasileira de Biologia, v. 59, n. 2, 1999, p 329-342.

RODRIGUES, R.R.; GANDOLFI, S. Conceitos, tendências e ações para a recuperação de florestas ciliares. In: RODRIGUES, R.R.; LEITÃO FILHO, H. de F. (Org.). Matas ciliares: conservação e recuperação. São Paulo: EDUSP: FAPESP, 2001. cap. 15.1 , p. $235-247$.

SAMPAIO, A.C.F. et al. Espécies exóticas invasoras na arborização de vias públicas de três bairros de Campo Mourão-PR. Campo Digit@1, v. 6, n. 1, p. 31-43, 2011.

SANTANA, O.A.; ENCINAS, J.I. Levantamento das espécies exóticas arbóreas e seu impacto nas espécies nativas em áreas adjacentes a depósitos de resíduos domiciliares. Biotemas, v. 21, n. 4, p. 29-38, 2008.
SÃO PAULO (Estado). Secretaria do Meio Ambiente. Resolução SMA n. 21, de 21/11/2001. Fixa orientação para o reflorestamento heterogêneo de áreas degradadas e dá providências correlatas. Disponível em: $\quad<\mathrm{http}: / / \mathrm{ttp}: / /$ licenciamento.cetesb.sp.gov.br/ legislacao/estadual/resolucoes/2001_Res_ SMA_21.pdf.> Acesso em: 21 abr. 2012.

SILVA, I.C. Caracterização fisionômica de fragmentos vegetacionais do distrito de Rubião Júnior, município de Botucatu, São Paulo. 2010. 116 f. Dissertação (Mestrado em Ciências Biológicas) - Instituto de Biociências, Universidade Estadual Paulista, Botucatu.

SILVA, R.F.B. Planejamento do uso do solo em uma bacia hidrográfica para conservação dos recursos hídricos. 2011. 86 f. Dissertação (Mestrado em Agronomia/Irrigação e Drenagem) Faculdade de Ciências Agronômicas, Universidade Estadual Paulista, Botucatu.

SOKAL, R.R.; ROHLF, F.J. Biometry: the principles and practice of statistics in biological research. 3rd ed. New York: W. H. Freeman, 1995. 887 p.

SOSCUESTA. SOS Cuesta de Botucatu. Córrego da Cascata: um rio limpo na área urbana de Botucatu. Botucatu, 2013. 360 p.

SOUZA, A.J. Botucatu: 147 anos na visão de nossas personalidades. In: FIGUEIROA, J.C.; VIEIRA, J.C.S.; RAMOS, M.D. Botucatu: história de uma cidade. Botucatu, 2005. 476 p.

SOUZA, A.J. et al. Aspectos físicos do município de Botucatu-SP. Ciência Geográfica, v. 9, n. 1, p. 54-75, 2003.

TEIXEIRA, A.P.; RODRIGUES, R.R. Análise florística e estrutural do componente arbustivo-arbóreo de uma floresta de galeria no município de Cristais Paulista, São Paulo-SP, Brasil. Acta Botanica Brasilica, v. 20, n. 4, p. 806-813, 2006. 
BELLUTA, I. et al. Vegetação ripária do córrego Cintra, Botucatu - SP

TUBELIS, A.; NASCIMENTO, F.J.L.; FOLONI, L.L. Parâmetros climáticos de Botucatu. Botucatu: FCA/UNESP, 1971. 24 p.

VITAL, T.R.A. et al. Produção de serrapilheira e ciclagem de nutrientes de uma floresta estacional semidecídual em zona ripária. Revista Árvore, v. 28 , n. 6, p.793-800, 2004. 